\title{
Should Anthroposophic Medicinal Products Be Regulated in Europe?
}

\author{
Geneviève Michaux \\ Counsel, Hunton \& Williams, Brussels, Belgium
}

\begin{abstract}
European Commission's reports suggest that the European Union should address the status of anthroposophic products, i.e. products that are developed, manufactured and prescribed in accordance with the holistic approach on which anthroposophic medicine is based. Anthroposophic products cannot be placed as such on the European market because they cannot meet the marketing authorisation or even registration requirements set out by European or national pharmaceutical law. Yet, the 95-year European tradition and good safety profile of anthroposophic products justify giving them an easier access to market. Such access can result from specific rules on anthroposophic products, but can be more efficiently achieved by encouraging the Member States to better apply the existing rules on marketing authorisation procedures or on registration of homeopathic and traditional herbal medicinal products, or by including anthroposophic substances, manufacturing methods or uses in monographs.
\end{abstract}

\section{Keywords}

medicinal products - European law - anthroposophic medicine

\section{Introduction}

In December 2014, the European Commission ('Commission') released a study on the availability of medicinal products in the European Union ('E U') ('Study

1 The term 'EU' refers to the European Economic Area ('EEA'), i.e., the Member States of the EU plus the three EFTA countries (Iceland, Liechtenstein, Norway).

(C) Geneviève Michaux, 2016 | DOI 10.1163/15718093-12341408

This is an open access article distributed under the terms of the Creative Commons Attribution 4.o. Unported (CC-BY-NC 4.0) License. http://creativecommons.org/licenses/by-nc/4.o/ como4/26/2023 01:11:21PM 
on Availability'). ${ }^{2}$ That study notably covers 'homeopathic and anthroposophic medicinal products' ('HAM Ps') and concludes 'to improve the national implementation of simplified procedures for herbal medicinal products and HAM Ps'. In September 2008, the Commission had published a report on traditional herbal medicinal products that concluded on the need to assess 'the suitability of a separate legal framework for products of certain traditions', i.e., anthroposophic, Ayurvedic and traditional Chinese medicinal products. ${ }^{3}$ So, six years apart, the Commission has highlighted that anthroposophic products should be better regulated in the EU.

Anthroposophic medicine has now been used for decades in European countries. This non-conventional medicine is based on a holistic approach, and anthroposophic products are developed, manufactured and prescribed in accordance with this approach.

Like homeopathic and traditional herbal medicinal products, anthroposophic products cannot meet the requirements for marketing authorisation ('MA') set out by pharmaceutical law, but unlike those other non-conventional products, EU pharmaceutical law does not allow their registration under adapted safety and efficacy requirements. As a result, anthroposophic products that do not qualify as homeopathic or traditional herbal products, or do qualify but do not meet the national registration or MA requirements specific to those products, may not be placed on the EU market.

The 95-year European tradition and outstanding safety record of anthroposophic products justify granting them easier access to the EU market, especially as they improve the quality of life of patients with heavy pathology or treatment. ${ }^{4}$ Such easier access can be achieved in several ways that entail either adopting specific rules on anthroposophic products or better applying the existing rules on MA procedures or on registration of homeopathic and traditional herbal products, and, in parallel, expanding homeopathic and herbal

2 Matrixx Insight, 'Study on the Availability of Medicinal Products for Human Use', 21 December 2012, p. 64 .

3 European Commission, Communication from the Commission to the Council and the European Parliament concerning the Report on the experience acquired as a result of the application of the provisions of Chapter 2a of Directive 2001/83/EC, as amended by Directive $2004 / 24 / E C$, on specific provisions applicable to traditional herbal medicinal products - Document on the basis of Art. 16i of Directive 2001/83/EC, 29 September 2008 (сом (2008) 584 final).

4 For example, they also avoid antibiotic resistance (see the studies referenced in ECHAMP, The Contribution of homeopathic and anthroposophic medicine to major EU health challenges - some scientific references, 2015). 
monographs to anthroposophic substances, methods and uses. The latter option is more efficient and should be encouraged by the Commission.

This article is presented in three parts: (1) an explanation of the specific features of anthroposophic products; (2) an overview of their current legal regime in Europe; and (3) proposals for solutions to enhance the availability of anthroposophic products in the EU.

2

\section{What Are Anthroposophic Products?}

\subsection{Anthroposophic Medicine - An Old but Modern Concept}

Anthroposophy started in Switzerland in the 1920s and has gradually both expanded to all parts of the world and become an established practice and a recognised subject for medical studies. Overall, anthroposophic medicine has become part of the European health environment. Anthroposophic products are regularly used in hospitals, and certain are widespread. For example, Viscum Album Extracts (mistletoe) is used as part of the treatment of around $50-70 \%$ of all oncology patients in Germany and Switzerland. Yet, anthroposophy remains a minority medicine and, as such, the subject of doubt and criticism. Non-conventional medicines ${ }^{5}$ are generally criticised due to their differences with conventional medicine, in particular because they are not exclusively based on scientific evidence. Also, certain non-conventional medicines are seen as somewhat irrational and philosophical due to their holistic approach and spiritual dimension. However, anthroposophic medicine embraces a very modern concept that integrates conventional medicine and an individualised complementary approach which includes all dimensions of the patient - physical, emotional, mental and spiritual.

\subsection{Anthroposophic Products}

Anthroposophic treatments are multimodal and generally include anthroposophic products.

Anthroposophic products are prepared individually for a specific patient or manufactured in a standardised way. Typically, over-the-counter products are standardised products for diseases such as minor sleeping problems, skin

5 E. Ernst, K.L. Resch, S. Mills et al., 'Complementary medicine - a definition', Br J Gen Pract (45) (1995) 506. Complementary and alternative medicines ('CAM') are '[d]iagnosis, treatment and/or prevention which complements mainstream medicine by contributing to a common whole, by satisfying a demand not met by orthodoxy or by diversifying the conceptual frameworks of medicine'. 
problems or eye irritations. Prescription products are individualised products for diseases such as hyperactive bladder, insomnia, cardiovascular or gynaecologic problems. They are usually authorised as complementary therapy but may also be first option treatments. Importantly, most anthroposophic products are developed without therapeutic indications. They are prescribed by conventional doctors, homeopaths, phytotherapists and, of course, anthroposophic doctors (doctors who studied a three-year training in anthroposophic medicine).

\subsection{What Is Unique about Anthroposophic Products?}

Like other non-conventional medicinal products, anthroposophic products can claim a long tradition of medical use, have few adverse effects and are cheaper than conventional medicinal products, but the demonstration of their efficacy in accordance with standards that have been adopted for conventional medicinal products, is a challenge (see below). However, anthroposophic products contain substances, dilution levels, manufacturing methods and descriptions of indications that are specific to anthroposophic medicine.

Factual information on anthroposophic medicine and products may be found on the website of the European Coalition on Homeopathic and Anthroposophic Medicinal Products ('ECHAMP') 6 or of the International Anthroposophic Association of Pharmacists ('IAAP'), a non-profit association of pharmacists committed to promote anthroposophic medicine and products. $^{7}$

\subsubsection{Pharmaceutical Quality}

Anthroposophic products contain raw materials from animal, vegetal or mineral origin, either as found, or transformed on the basis of an anthroposophic pharmacy.

They are manufactured according to homeopathic or anthroposophic manufacturing methods, and their quality is controlled under Good Manufacturing Practice ('GMP'). During the last decades, many anthroposophic substances and manufacturing methods have been integrated into national pharmacopeias but as homeopathic substances or manufacturing methods. To date, neither a Member State nor the European Directorate for the Quality of Medicines ('EDQM') has adopted an official anthroposophic pharmacopoeia or monograph. The Swiss Pharmacopoeia, however, includes a monograph with the

6 See www.echamp.eu, accessed on 3 November 2015.

7 See www.iaap.org.uk, accessed on 3 November 2015. 
definition of 'Anthroposophic Preparations'8 and a chapter on 'Manufacturing methods for anthroposophic preparations'. ${ }^{9}$ Furthermore, the IAAP has developed an 'Anthroposophic Pharmaceutical Codex' ('APC') that gives an overview of substances and methods used in the manufacture of anthroposophic products as well as related quality parameters; the APC is officially recognised by the Medicines Agencies in Brazil and New Zealand.

\subsubsection{Safety}

Studies have analysed the safety of anthroposophic products and concluded on an overall safety level similar to that of homeopathic and herbal products. In general, anthroposophic products have very low rates of adverse drug reactions ${ }^{10}$ even for the highest-risk anthroposophic products (those administered by injections), the risk of side effects is $0.000036 \% .^{11}$

Furthermore, the same pharmacovigilance requirements are de facto to anthroposophic products as to medicinal products. Doctors, pharmacists and patients report adverse reactions to the manufacturer and health authorities.

\subsubsection{Efficacy}

Efficacy of anthroposophic products has been studied. In 2011, a health technology assessment report had identified 265 clinical studies on the efficacy and effectiveness of anthroposophic medicine and concluded on a predominantly positive outcome, ${ }^{12}$ despite the negative conclusion of a Cochrane review of viscum album.

8 'Anthroposophic preparations are conceived, compounded and produced according to the principles of the anthroposophic understanding of mankind and nature. Their use is based on this understanding. An anthroposophic preparation can be a single substance but also a combination with more substances and/or excipients. Concerning the active substances the medicinal product can be the substance itself or a substance which has been processed according to an anthroposophic method of preparation. Excipients can be water, lactose, serum, ethanol, glycerol or other substances that help producing the different dosage forms.' Ph. Helv. 11, Suppl. 11.1, (December 2013) 306.

$9 \quad$ 11.1/17.07.00, ibid.

10 E. Jeschke, M. Schaefer, C. Lueke, T. Ostermann and H. Matthes, 'EVAMED — A prescription-based electronic system for reporting drug events in complementary medicine', Drug Saf (29) (2006) 341-370.

112012 review published by the Deutsche Apotheker Zeitung. See also The Medical Section of the School of Spiritual Science, Goetheanum, 'Anthroposophic Medicines — their origin, production and application', (2003), p. 15.

12 G.S. Kienle, A. Glockmann, R. Grugel, H.J. Hamre and H. Keine, "Klinische Forschung zur Anthroposophischen Medizin - Update eines 'Health Technology Assessment' Berichts und Status Quo', Forsch Komplementmed (18) (2011) 4. 
Efficacy studies on anthroposophic products are difficult to conduct, for the same reasons as they are difficult to conduct on homeopathic or traditional herbal products; anthroposophic medicine is based on a holistic approach and relies not only on the medicinal product but also on the patient's response to that product. Comparative efficacy studies with conventional medicinal products are even more complex. ${ }^{13}$ Money is also an issue. Scientific research in non-conventional medicinal products does not benefit from the same broad funding as scientific research in conventional products, and the low profit margins of anthroposophic products do not support expensive trials. In addition, the effects of the products often are more subtle than those of conventional medicinal products, thereby requiring a large number of trial subjects to achieve statistical significance.

For most indications, the evidence of efficacy in accordance with the same standards as conventional medicinal products is not only inappropriate but also disproportionate given their low risk profile and long tradition of medicinal use. Yet, single randomised clinical studies have been conducted that demonstrate efficacy in major indications. For instance, the use of Viscum Album Extracts (mistletoe) in oncology patients was reviewed in over 3,500 scientific publications, and its positive impact on quality of life and other relevant parameters were systematically confirmed. ${ }^{14}$ Recent clinical studies have showed an increased overall survival in patients with pancreatic cancer who are taking Viscum Album in addition to their conventional treatment. ${ }^{15}$

However, evidence based on scientific literature on effectiveness or clinical experience (observational studies, case reports) seems better suited to the characteristics of anthroposophic products.

\section{3}

\section{Authorisation of Anthroposophic Products}

Anthroposophic products are recognised but not specifically regulated by EU pharmaceutical law. If they meet the criteria to qualify as homeopathic or traditional herbal medicinal products, they benefit from the simplified legal regime

13 E. Ernst, M.H. Cohen and J. Stone, 'Ethical problems arising in evidence based complementary and alternative medicine', Journal of Medical Ethics 30(2)(2004) 156-159.

14 G. Kienle, F. Berrino, A. Buessing, E. Portalupi, S. Rosenzweig and H. Kiene, 'Mistletoe in cancer — a systematic review on controlled clinical trials', Eur JMed Res (8) (2003) 109-119.

15 W. Trogen, D. Galun, M. Reif, A. Schumann, N. Stankovic and M. Milicevic, 'Viscum Album (L) extract in therapy in patients with locally advances or metastatic pancreatic cancer: A randomised clinical trial on overall survival', Eur J Cancer 49 (18) (2013), 3788-3797. 
applicable to those products. If they do not, standard MA procedures apply. In practice, this results in many anthroposophic products not being authorised.

\subsection{Anthroposophic Products At the European Level}

Medicinal products are regulated by Directive 2001/83/EC ('Directive') ${ }^{16}$ or Regulation (EC) No $726 / 2004,{ }^{17}$ depending on whether they are authorised at the national or European level. Only the Directive is relevant for purposes of this article.

\subsubsection{Marketing Authorisation Procedures}

As a general rule, the marketing of medicinal products is subject to the grant of an MA by the competent national authority (typically the Medicines Agency).

The Directive sets out the MA procedures and requirements. It institutes different types of MA applications, and each type requires different information and documents. The Annex to the Directive imposes the Common Technical Document ('СтD') format and details the information and documents relating to quality, safety and efficacy that are required for each type of MA application or of medicinal products.

A 'full MA application' is the most demanding in terms of evidence. Safety is to be supported by non-clinical data, and efficacy is to be supported by clinical data. The Directive, however, allows the evidence of safety and/or efficacy to be brought by other, easier means for the other types of MA applications, subject to certain conditions being met. In the case of a well-established substance, the applicant company may file a so-called 'bibliographic' MA application. ${ }^{18}$ Specifically, where a medicinal product contains an active substance with a well-established medical use (medical use, in a systematic and documented way, for more than 10 years in the $\mathrm{EU}$ ), the non-clinical and clinical data in

16 Directive 2001/83/EC of the European Parliament and the Council of 6 November 2001 on the Community code relating to medicinal products for human use.

17 Regulation (EC) No 726/2004 of the European Parliament and of the Council of 31 March 2004 laying down Community procedures for the authorisation and supervision of medicinal products for human and veterinary use and establishing a European Medicines Agency.

18 By way of derogation from Art. 8(3)(i), and without prejudice to the law relating to the protection of industrial and commercial property, the applicant shall not be required to provide the results of pre-clinical tests or clinical trials if he can demonstrate that the active substances of the medicinal product have been in well-established medicinal use within the Community for at least ten years, with recognised efficacy and an acceptable level of safety in terms of the conditions set out in Annex I. In that event, the test and trial results shall be replaced by appropriate scientific literature. 
the MA dossier may be replaced by published scientific literature. The requirements of safety and efficacy are not relaxed; simply, the scientific publications prove that the required non-clinical and clinical tests have been conducted previously, which justifies relieving the (bibliographic) applicant from conducting those tests and studies once again. ${ }^{19}$

The Directive also contains specific chapters on homeopathic medicinal products (Arts. 13-16) and herbal medicinal products (Arts. 16a-16i) that, given the characteristics of those products, allow registration rather than authorisation.

\subsubsection{Homeopathic Medicinal Products}

Homeopathic medicinal products are legally defined as:

[a]ny medicinal product prepared from substances called homeopathic stocks in accordance with a homeopathic manufacturing procedure described by the European Pharmacopoeia or, in the absence thereof, by the pharmacopoeias currently used officially in the Member States. A homeopathic medicinal product may contain a number of principles (emphasis added). ${ }^{20}$

Homeopathic medicinal products may be authorised under the standard MA procedure or registered under a simplified procedure. Those that have been registered or authorised in accordance with national legislation before 1994, are not subject to the Directive. ${ }^{21}$

Under Article 14 of the Directive, homeopathic products may benefit from the registration procedure if the following conditions are met: the product (a) is to be administered orally or externally, (b) has no specific therapeutic indication, and (c) has a sufficient degree of dilution ${ }^{22}$ to guarantee its safety. Under the registration procedure, not all safety studies have to be provided if an acceptable level of safety can otherwise be supported, and efficacy need

19 CJEU, 5 October 1995, Scotia, C-440/93; CJEU, 23 October 2014, Olainfarm, C-104/13.

$20 \quad$ Art. 1(32) of the Directive.

21 Homeopathic medicinal products were first regulated by Council Directive 92/73/EEC of 22 September 1992 widening the scope of Directives 65/65/EEC and 75/319/EEC on the approximation of provisions laid down by law, regulation or administrative action relating to medicinal products and laying down additional provisions on homeopathic medicinal products. Directive 92/73 was repealed by the Directive.

22 Not more than one part per 10 '000 of the mother tincture or, in the case of substances subject to medical prescription, more than 1/100 of the smallest dose used in allopathy. 
not to be demonstrated. Quality is typically demonstrated by compliance with homeopathic monographs.

In practice, the registration procedure is lengthy (12 to 25 months) in several Member States. More importantly, although Member States may not impose registration requirements other than those set out in Article $14,{ }^{23}$ some still do, and those additional — and divergent — national requirements make the registration procedure very burdensome. They also undermine a harmonised registration system for homeopathic products, and that disharmony cannot be corrected because even though the registration benefits from the mutual recognition system, disagreements among Member States may not be escalated to the Commission. The Heads of Medicines Agencies ('HMA') has set up a working group for homeopathic products ('HM PWG') that is meant to address issues relating to homeopathic products ${ }^{24}$ and could help the efficiency and harmonisation of the registration procedure. In practice, however, the HMPWG lacks sufficient resources to disseminate its work and to tackle all relevant issues.

If the conditions of Article 14 are not met (e.g., for injectables, concentrated products, products with a therapeutic indication), the standard MA procedures apply, but Article 16(2) of the Directive allows each Member State to apply specific rules for demonstrating safety and/or efficacy 'in accordance with the principles and characteristics of homeopathy as practised in that Member State'. Unfortunately, not all Member States have implemented Article 16(2), and the few national implementations are divergent.

The Study on Availability highlights the shortcomings of the procedures for homeopathic products.

3.1.3 Traditional Herbal Medicinal Products

Herbal medicinal products are legally defined as

[a]ny medicinal product, exclusively containing as active ingredients one or more herbal substances or one or more herbal preparations, or one or more such herbal substances in combination with one or more such herbal preparations. ${ }^{25}$

23 CJEU, 12 May 2005, Meta Facker v. Germany, C-444/03 (general awareness of the homeopathic medicinal product). This is confirmed in Sect. 3.3, Chapter I - Marketing authorisation (July 2015), Notice to Applicants.

24 See www.hma.eu, accessed on 3 November 2015.

25 Art. 1(30) of the Directive. Herbal preparations are defined as "[p]reparations obtained by subjecting herbal substances to treatments such as extraction, distillation, expression, fractionation, purification, concentration or fermentation. These include comminuted or 
Pursuant to Article 16(a)(1), an herbal medicinal product qualifies as a 'traditional herbal medicinal product' and, as such, may benefit from a 'traditionaluse registration' procedure if the following conditions are met: (i) minor indications; ${ }^{26}$ (ii) the product is exclusively for administration in accordance with a specified strength and posology; (iii) the product is an oral, external and/or inhalation preparation; (iv) the period of traditional use has elapsed; and $(\mathrm{v})$ the data on the traditional use is sufficient. Under the registration procedure, the applicant company has to demonstrate quality, but non-clinical and clinical data is not required, provided that sufficient evidence proves a medical use of the substance for at least 30 years, including 15 years in the EU. Such a long tradition of use allows one to assume that the product is safe and efficacious.

When assessing applications for traditional-use registration, the Member States must take into account the Community monographs or, if not available, 'other appropriate monographs, publications or data'. Community herbal monographs are established by the European Medicines Agency ('EMA'). About 150 monographs have been developed so far. Where a national registration is based on a monograph or where the substance or preparation of substances is on the Commission's official list of herbal substances, preparations or combinations thereof, the other Member States must recognise that registration. Otherwise, they only have to take it into account.

Again, in practice, the traditional-use registration procedure takes longer than expected ( 9 to 32 months), its access is subject to highly restrictive conditions and fees often are prohibitive for SMESs.

\subsubsection{Anthroposophic Products}

The Directive contains no specific rules on anthroposophic products except for Recital 22. Recitals 21 to 25 concern homeopathic medicinal products, and Recital 22 states that

[t]he anthroposophic medicinal products described in an official pharmacopoeia and prepared by a homeopathic method are to be treated, as regards registration and marketing authorization, in the same way as homeopathic medicinal products.

powdered herbal substances, tinctures, extracts, essential oils, expressed juices and processed exudates.'

26 Indications exclusively appropriate to traditional herbal products which, due to their composition and purpose, are intended and designed for use without the supervision of a medical practitioner 
Recital 22 expressly recognises anthroposophic products, but it is not a sufficient basis to define them and require harmonised rules as it is not binding on the Member States, ${ }^{27}$ and only clarifies the homeopathic rules. Also, Recital 22 refers to (i) homeopathic methods and not all anthroposophic products follow homeopathic manufacturing methods; and to (ii) official pharmacopoeia and not all anthroposophic active substances are described in the European Pharmacopoeia or in a national pharmacopoeia.

Anthroposophic products therefore remain subject to standard MA procedures unless they qualify as homeopathic or traditional herbal medicinal products and meet the conditions for benefiting from the specific homeopathic or traditional herbal legal regimes. This has been confirmed by the Court of Justice of the European Union ('CJEU') in the Antroposana case ${ }^{28}$ and reiterated by the Commission in the Notice to Applicants. ${ }^{29}$

\subsection{Anthroposophic Products at the National Level}

In the absence of specific European rules, the status of anthroposophic products remains unclear and their marketing remains a challenge.

3.2.1 Are They Medicinal Products?

The very nature of anthroposophic products may vary from country to country. Most Member States consider them as medicinal products, ${ }^{30}$ be it magistral preparations. In a few Member States, however, certain anthroposophic products can be considered as medical devices due to their mechanism of action, or as food supplements due to their ingredients.

\subsubsection{Marketing Authorisation}

As medicinal products, anthroposophic products are subject either to the standard MA procedures, or to the registration procedure for homeopathic or traditional herbal medicinal products as implemented into national law, or to a 'loose' MA procedure for homeopathic products resulting from the national implementation of Article 16(2). In the absence of specific rules in the

27 CJEU, 19 November 1998, Nilsson and others, C-162/97.

28 CJEU, 20 September 2007, The Netherlands v. Antroposana and others, C-84/o6; I. DoddSmith, 'Complementary medicines', Pharma Law Insight, July/August 2007, 4.

29 Ibid.

30 A medicinal product is legally defined as 'any substance or combination of substances (a) presented as having properties for treating or preventing disease in human beings; or (b) which may be used in or administered to human beings either with a view to restoring, correcting or modifying physiological functions by exerting a pharmacological, immunological or metabolic action, or to making a medical diagnosis'. 
Directive, the Member States may not adopt a national specific legal regime for anthroposophic products. ${ }^{31}$

In general, bibliographic MA applications are the best option for products that contain substances with a longstanding medical use and whose therapeutic efficacy is difficult to demonstrate on the basis of criteria designed for conventional medicinal products (because the MA dossier might contain scientific literature instead of non-clinical and clinical data). Yet, in practice, bibliographic MA applications do not work for anthroposophic products, primarily because some national regulators still require new clinical data in addition to scientific literature. In the Orphacol I case, the General Court went in the opposite direction and ruled that the data submitted to support a bibliographic MA application need not to be comprehensive if the applicant justifies why the demonstration of an acceptable level of safety and/or efficacy can nevertheless be supported. ${ }^{32}$ Although the Orphacol I case concerned an orphan medicinal product, the Court's rationale could extend to other categories of products, including anthroposophic products. For those products, the lack of studies could be justified by the (quasi) impossibility to conduct clinical trials due to the specific nature of the products, and be 'compensated' by data generated from other types of studies, such as prospective observational studies, prospective scientific evaluations of case reports or retrospective evaluations of case reports.

The national implementations of Article 16(2) of the Directive could also have been a solution, but many Member States have not yet used that opportunity, and those that did have imposed divergent requirements.

\subsubsection{Registration}

Anthroposophic products can be registered through the simplified regimes for homeopathic or traditional herbal products, but, in practice, only a few anthroposophic products qualify as traditional herbal medicinal products due to their composition (not exclusively herbal ingredients) or traditional use (different from the use set forth in the herbal monographs). More anthroposophic products qualify as homeopathic products, but many do not, due to their composition (substances, dilution levels) or manufacturing processes.

Moreover, the national implementations of the rules on registration are so demanding that even fewer anthroposophic products are registered than could be if the national rules were less stringent.

\footnotetext{
31 Notice to Applicants, Vol. 2A Eudralex. Sect. 5.4, Chapter I — Marketing authorisation (July 2015).

GC, 4 July 2013, Laboratoires CTRS, T - 301/12.
} 


\subsubsection{Current Situation in Europe}

To date, many anthroposophic products have been authorised in several European countries, but never as such; most have been registered as homeopathic medicinal products.

In the EU, Germany has the most 'achieved' legal regime for anthroposophic medicine because it is one of the three 'special therapeutic systems' expressly recognised by the Medicine Act (Arzneimittelgesetz or 'AMG') and the Code of Social Law (Sozialgesetzbuch).

The AMG expressly considers phytotherapy, homeopathy and anthroposophic medicine as specific and different therapeutic systems. In line with this approach, Section 4(33) AMG defines anthroposophic medicinal products. ${ }^{33}$ The definition is based on the specific characteristic of anthroposophic products - to be developed and intended for use according to the principles of anthroposophic understanding of humans and nature. ${ }^{34}$

Despite the express recognition of anthroposophic medicine and products, no specific rules on the authorisation or registration of anthroposophic products have been adopted. Sections 25(6) and (7) AMG require the Medicines Agency ('BfArM') to consult 'a marketing authorisation commission' before adopting a decision on the MA of a medicinal product attributed to a special therapeutic system. Commission $\mathrm{C}$ ensures that the 'individual peculiarities' of anthroposophic medicinal products are taken into account in the scientific assessment of the MA dossier, and has established anthroposophic 'monographs' that cover safety and efficacy (indications, contra-indications, dosage, ... .). ${ }^{35}$ This system somewhat facilitates the authorisation of anthroposophic products in Germany but only as homeopathic products.

No specific anthroposophic pharmacopoeial monographs have been adopted either. The German Homeopathic Pharmacopoeia contains monographs that historically have integrated anthroposophic manufacturing methods and substances, but those monographs currently are presented as homeopathic monographs.

See also Section 39(2)(7a) AMG. The BfArM may refuse an application for registration of an homeopathic medicinal product where 'the use of the individual active substances as homeopathic or anthroposophic medicinal products is not generally known.'

An anthroposophic medicinal product is a "medicinal product which has been developed according to the anthroposophic understanding of humans and nature, according to a European Pharmacopoeia or, in the absence thereof, in accordance with a homeopathic manufacturing practice described in the pharmacopoeias currently used officially in the Member States of the EU, or according to a special anthroposophic manufacturing procedure, and which is intended for use according to the principles of anthroposophic understanding of humans and nature"

See www.bfarm.de, accessed on 3 November 2015. 
So far, Switzerland is the only European country that recognises and regulates anthroposophic products as such. A reference to treatments with complementary and alternative medicines was incorporated into the Swiss Constitution further to a national referendum held in 2009, ${ }^{36}$ and the Swiss health system expressly recognises four categories of complementary and alternative medicines, including anthroposophic medicine.

The Swiss MA system is very similar to the EU MA system. Medicinal products may only be placed on the market after having been authorised by the Swiss Agency for Therapeutic Products ('Swissmedic'). The same rule applies to complementary and alternative medicinal products, but their authorisation has been significantly simplified by the Ordinance on Complementary and Herbal Medicines (Verordnung des Schweizerischen Heilmittelinstituts über die vereinfachte Zulassung von Komplementär-und Phytoarzneimitteln or ' $\left.\mathrm{KPAV}^{\prime}\right) .{ }^{37}$

The K PVA defines 'anthroposophic medicinal product' 38 and sets out a legal regime that recognises their specific nature and low level of risks.

Active substances must be manufactured using homeopathic or anthroposophic methods and be obtained from (i) raw materials included in the official list of homeopathic or anthroposophic substances ('HAS') or (ii) other raw materials if they are sufficiently recognised in homeopathic or anthroposophic medicine. Anthroposophic products with therapeutic indication are subject to a registration procedure (Annex 1 to the KPVA), ${ }^{39}$ and anthroposophic medicinal products without therapeutic indication are subject to an even more

36 Art. 118a of the Federal Constitution of the Swiss Confederation: 'The Confederation and the Cantons shall within the scope of their powers ensure that consideration is given to complementary medicine'.

37 See http://www.admin.ch/opc/de/classified-compilation/20051631/index.html, accessed on 3 November 2015 .

38 [m] edicine products, whose active substances are manufactured by a homoeopathic manufacturing procedure, or according to an anthroposophic manufacturing procedure described in the German Homoeopathic Pharmacopoeia or in the British Homoeopathic Pharmacopoeia or according to a special anthroposophic manufacturing procedure and that are composed and developed according to the anthroposophic knowledge of man, animal, substance and nature and meant to be used according to these principles.

39 Annex 1 sets out the information and documents to be submitted with the registration application. Safety data from scientific literature or non-clinical tests is required unless the safety profile is known, i.e., the substance is approved in a medicinal product or the raw materials are known in homeopathy or anthroposophic medicine and are listed in the HAS. Efficacy may be demonstrated by clinical data or as required in the monographs from Commission C of the BfArM or by scientific literature where the substance has a traditional use. 
simplified registration procedure, or notification procedure (Annex 2 to the KPVA). ${ }^{40}$ According to Swissmedic, the majority of anthroposophic products without specific therapeutic indication(s) qualify for the notification procedure. $^{41}$

Switzerland not being a part of the EU, Swiss registrations of anthroposophic products may not be recognised by the Member States of the EU.

Anthroposophic products that are authorised or registered in Switzerland or in one Member State as homeopathic or traditional herbal products, or through bibliographic MA applications, could be imported to another Member State under the national legal regime(s) implementing Article 5 of the Directive (exemption from ma based on patient therapeutic needs). This way of gaining access to another EU national market however cannot be a long-term solution, especially because those national regimes not only should remain exceptional and be restricted to products filling therapeutic needs, ${ }^{42}$ but also limit the quantities of products to be supplied to the national market.

\section{$4 \quad$ Should Anthroposophic Products Be Regulated?}

The absence of a clear or appropriate legal regime for anthroposophic products hinders their availability in the EU. Many arguments support regulating anthroposophic products as such.

Anthroposophic medicine is an established practice that has become part of the European health environment, be it a very little part. The safety and efficacy of anthroposophic products is demonstrated by scientific studies and the regular use of those products by qualified doctors since the 1920s. More importantly, no objective arguments explain why anthroposophic products should be subject to a (much) heavier regulatory regime than homeopathic or

40 The requirements for the simplified registration procedure are the following: (i) no branding or posology; (ii) the excipients are in a monograph in the European, Swiss, French or German pharmacopeia or are authorised by SwissMedic; (iii) documentation regarding the quality of the product (manufacturing and controls) is available upon request; and (iv) an MA procedure has not been rejected due to qualitative or toxic defects. The notification procedure (Meldeverfahren) applies when the following additional requirements are met: the raw materials are listed in the HAs list; and the active substance has the concentration or dilution level indicated in Annex 4 to the KPVA (or higher).

41 See https://www.swissmedic.ch/zulassungen/o0153/oo189/oo19o/oo286/index.html? lang=en, accessed on 3 November 2015 .

42 CJEU, 11 April 2013, Novartis v. Apozyt, C-535/11; CJEU, 29 March 2012, Commission v. Poland, C-185/10; CJEU, 8 November 2007, Ludwigs Apotheke v. Juers Pharma, C-143/o6. 
traditional herbal products. On the contrary, the characteristics shared with those products justify subjecting anthroposophic products to the same or very similar simplified and more appropriate regulatory pathways.

On the one hand, Recital 21 of the Directive specifies that the particular characteristics of homeopathic medicinal products (very low level of active principles and difficulty of applying the conventional statistical methods relating to clinical trials) make it desirable to provide a special, simplified registration procedure for homeopathic products without therapeutic indications and in a pharmaceutical form and dosage which do not present a risk for the patient. Certain anthroposophic products share the same characteristics (i.e., low risks and difficulty in conducting clinical trials) that justify the implementation of a registration procedure or a simplified MA procedure pursuant to Article 16(2).

On the other hand, Directive 2004/24/EC, ${ }^{43}$ that amended the Directive to introduce specific provisions on traditional herbal medicinal products, was intended to address the specific situation of herbal products that were based on a long tradition. At the time, other products were already in a similar situation, i.e., having a long tradition as medicinal products but not fulfilling the requirements for a full MA (even a bibliographic MA), but the scope of Directive 2004/24 was deliberately limited to traditional herbal medicinal products in order to gain experience with the 'traditional use' procedure. This is clearly reflected in Article $16 \mathrm{i}$ of the Directive. ${ }^{44}$

As recognised by the 2008 Commission report on Article 16i, anthroposophic products can claim a long traditional use and, as such, should also be given access to a registration procedure.

An extension of the traditional use registration procedure to Asian tradition herbal products, such as Chinese or Ayurvedic medicinal products, is currently under discussion (see the HMPC's Action Plan 2016). The EU cannot logically facilitate the marketing of such Asian tradition products, but refuse the same for products based on European tradition.

43 Directive 2004/24/EC of the European Parliament and of the Council of 31 March 2004 amending, as regards traditional herbal medicinal products, Directive 2001/83/EC on the Community code relating to medicinal products for human use.

44 [b]efore 30 April 2007, the Commission shall submit a report to the European Parliament and to the Council concerning the application of the provisions of this chapter. The report shall include an assessment on the possible extension of traditional-use registration to other categories of medicinal products. 
The adoption of a specific legal regime by each Member State is precluded by the CJEU ruling in the Antroposona case, but several options remain available that would facilitate the authorisation/registration of anthroposophic products in the EU. Two basic options are: (1) the adoption of new and specific rules, or (2) a better application of the existing rules.

\subsection{Adoption of Specific Rules}

Specific rules on anthroposophic medicinal products could be inserted in the Directive or be part of a broader Community act on traditional medicine.

\subsubsection{Introduction of a Specific Legal Regime in the Directive}

A special legal regime for anthroposophic products could be introduced in the Directive.

A new section could be added in Chapter 2 (Title III of the Directive) that explicitly covers anthroposophic medicinal products ('specific provisions applicable to anthroposophic medicinal products') and provides for a separate registration system for anthroposophic products. This registration system could be modelled on the homeopathic registration system, adding some of the rules from the traditional herbal medicinal products regime, such as the reliance on traditional use or the development of monographs. Alternatively, the sections dedicated to homeopathic and traditional herbal medicinal products could each be extended to anthroposophic products. A new paragraph could be added to each relevant provision in order to specify or tailor its application to anthroposophic products. This approach would clarify the links between anthroposophic products and homeopathic or traditional herbal medicinal products.

Either way, a legal definition of 'anthroposophic medicinal products' must be included in Article 1 of the Directive, and the registration process should benefit from the decentralised or mutual recognition procedure with referral of disagreements to the Commission.

\subsubsection{Specific Legal Regime in a New Community Act}

In its 2008 report on Article 16i, the Commission recommends:

On the other hand, it should be emphasised that Community legislation on medicinal products, in particular Directive 2001/83/EC laying down the procedures for placing products on the market, follows a 
product-specific approach and does not attempt to provide a framework for the regulation of traditions of medical practice.

During the public consultation, proponents of three traditional medical systems using products with a long-standing tradition expressed support for the global regulation of their traditions within the EU: anthroposophic, Ayurvedic and traditional Chinese medicine. It was suggested that proof of the plausibility of efficacy should not be by medicinal product, but by therapeutic approach.

Medical traditions such as those mentioned above are based on a holistic approach, and the set of requirements for the simplified registration procedure under Directive 2004/24/EC is not appropriate for a global regulation of such medical practices. The regulation of such traditions would demand a different approach from that introduced by Directive 2004/24/EC. Therefore, the Commission does not envisage extending the scope of the simplified registration procedure to cover traditional medical systems as such. Nevertheless, independently of this report, the suitability of a separate legal framework for products of certain traditions should be assessed.

In short, the European legislature could regulate all the complementary and alternative medicinal products, including anthroposophic products, in a new piece of legislation.

\subsection{Better Application of Existing Rules \\ 5.2.1 More Flexible Interpretation of the Rules on Bibliographic MA Applications}

The Member States could adopt a more flexible interpretation of the existing rules on bibliographic MA applications. In particular, they should not require more proof than published scientific literature, and published literature should not have to cover all non-clinical and clinical trials in cases where other relevant evidence, such as epidemiologic data, observational data or case reports, already demonstrates safety or efficacy.

\subsubsection{More Flexible Interpretation of the Rules on Registration of Homeopathic or Traditional Herbal Medicinal Products}

The Member States could also be more flexible when interpreting the existing rules on registration of homeopathic or traditional herbal medicinal products.

With regard to homeopathic products, the Member States could recognise pharmacopeia of third countries, such as Switzerland, or even the APC as 
supportive literature so that Article 14 of the Directive can apply to anthroposophic products that are manufactured according to those pharmacopeias or the APC. With regard to traditional herbal products, the Member States could add herbal preparations and indications from the anthroposophic herbal tradition to the herbal monographs.

5.2.3 More Effective Application of Article 16(2) of the Directive The Member States could rely on Article 16(2) of the Directive to acknowledge the specific features, in particular the specific manufacturing processes, of anthroposophic products when assessing MA applications for anthroposophic products that are close to homeopathic products. In practice, national authorities could accept scientific publications instead of non-clinical and clinical data as means of evidence of safety and efficacy; they could tailor the level of evidence to the therapeutic indication to be authorised; or they could accept specific manufacturing processes by considering the APC or the Swiss Pharmacopoeiea as supportive literature. Sweden has already started to move in that direction.

The Member States should also harmonise their requirements as much as possible.

\subsubsection{Limited Ground to Oppose Mutual Recognition}

Pursuant to Article 29(1) of the Directive as interpreted by the CJEU,${ }^{45}$ Member States may refuse to recognise authorisations or registrations granted by another Member State if the opposition is based on a serious potential risk to public health. That ground being the only one for refusing recognition, one may wonder how the decentralised or mutual recognition procedure can fail for homeopathic products as they are characterised by a low level of risks. Yet, it does. Again, a better application of Article 29(1), which is expressly applicable to homeopathic products under Article 13 of the Directive, would increase the number of anthroposophic products authorised in the EU, be it as homeopathic products.

\subsubsection{Anthroposophic Section in Monographs or Anthroposophic Monographs}

The national and European regulators could systematically include a section dedicated to anthroposophic substances, manufacturing methods or uses, in homeopathic and herbal monographs so that the rules on homeopathic or traditional herbal products become fully applicable to anthroposophic products as anticipated both in Recital 22 and at the time of adoption of the rules on 
traditional herbal products. Expanded monographs will help the Member States to apply Article 14 or Article 16(2) of the Directive to anthroposophic products. One might wonder why the HMPWG (HMA) does not recommend adding such anthroposophic sections in homeopathic monographs as several national authorities have done so in the past. One might also wonder why the HMPC (EMA) develops monographs for Chinese plants and yet does not acknowledge the well-known anthroposophic use of plants. ${ }^{46}$

Mix monographs, i.e., monographs that cover both herbal substances or processes and homeopathic substances or processes, as well as anthroposophic monographs, could also be established.

\section{Conclusion: Which Option Is Best?}

In light of the CJEU ruling in Antroposona, the adoption of specific rules on anthroposophic products requires some action at the European level. This option is the 'cleanest', but its implementation will require years and political support from the EU institutions.

A better application of the existing rules is a quicker solution that is also in line with the conclusion of the Study on Availability ('work to improve the national implementation of simplified procedures for herbal medicinal products and HAMPs'). This option is not easy because it requires an agreement or alignment among the Member States and they do not all share the same perspective on anthroposophic products, which means that a clear and understandable specific legal framework for anthroposophic products is less likely to be achieved. Yet, the conclusion of Case 6 in the Study on Availability is clear:

Given the demand for such products, there appears to be a need for further action in this area, which, according to consulted stakeholders, should focus on ensuring that the process of authorisation of herbal medicinal products and HAMPs is more consistent, both within the text of the existing provisions and between Member States.

A systematic extension of homeopathic and herbal monographs to anthroposophic substances, manufacturing methods or uses or the adoption of

46 Interestingly, while the focus of the Community herbal monographs is on the use of herbal products in Europe, discussions are ongoing to extend them to non-European traditional uses. The same trend is seen in the European Pharmacopoeia which includes about 50 monographs on quality of plants used in traditional Chinese medicine. 
anthroposophic monographs may be the least controversial option, although not the easiest as both the HM PC (EMA) and the HMPWG (HMA) - or even the EDQM - will have to be convinced to expand the monographs.

Overall, the availability of anthroposophic products on the EU market requires the Commission and the HMA to encourage, on the one hand, the Member States to better apply the existing rules of the Directive and, on the other hand, the HMPC and HMPWG to include anthroposophic sections in homeopathic and herbal monographs or even to adopt anthroposophic monographs. The conclusions of the Commission's report on Article 16i and of the Study on Availability should convince the Commission and the HMA to give such 'encouragement'. 